\title{
Development method of simulation software of landscape affecting traffic safety in traffic system
}

\author{
Yang Zhifa ${ }^{\mathrm{a}}$, Guan Xing ${ }^{\mathrm{b}}$ \\ State Key Laboratory of Automobile Dynamic Simulation, \\ Jilin University \\ Changchun, Jilin 130022, P.R.China; \\ ayangzf@jlu.edu.cn, ${ }^{\mathrm{b}} \mathrm{gx} @ 163 . c 0 m$ \\ Yang Zhifa ${ }^{\mathrm{a}}$, Li Shiwu ${ }^{\mathrm{d}}$ \\ Traffic and Transportation College, Jilin University \\ Changchun, Jilin 130022, P.R.China;
}

\begin{abstract}
Simulation is a resonable method to research the impact of landscape on traffic safety. In this paper, two different charts of main control program of the simulation program and chart of main simulation program are researched; the simulation program was built by Visual Basic and Access Database. The impact of vehicle speed, radius of curved road and landscape position on the risk probability of the road were analyzed by simulation. The results showed: when radius of curved road are same, the risk probability of the road with high road design speed was smaller than that of low one, for example it was reduced about $41.7 \%$ when the road design speed is $80 \mathrm{~km} / \mathrm{h}$ than that is $60 \mathrm{~km} / \mathrm{h}$; the risk probability of the road reduced about $58 \%$ at large radius curved road than small one when the landscape is in the same place and road design speed does not change.
\end{abstract}

Key words - Road safety, landscape, traffic safety, simulation software, development process

\section{INTRODUCTION}

Road landscape affects traffic safety by many ways, so research work on it would be restricted. The simulation technology for traffic system can make the scene, vehicle operation or accident reappear, and can avoid the risk of the experiment which real vehicle, so simulation is the best method to research the impact of road landscape on traffic safety. The simulation technology for traffic system (STTS) was developed with the development of computer technology from 1960's, it is a flexible experimental platform where road and traffic design combine together very good. According the describing levels of detail, STTS can be divided three types: macro-simulation, meso-simulation and micro-simulation [1]. According the difference of functions, STTS can be divided the following three types, one is driving simulator (DS) which focused on the automotive performance evaluation, typical results are the driving simulators of auto manufacturers and research department in Europe, America and Japan [2], ADSL DS of Jilin University of China belongs to this type too [3];

\author{
${ }^{\mathrm{d}} \underline{\text { swl@163.com }}$ \\ $\mathrm{Yu} \mathrm{Zhuo}^{3 *, \mathrm{c}}$, \\ 3 Basic Sciences College of ChangChun University of \\ Technology \\ Changchun, Jilin, P.R.China, ST:130012 \\ cyzf2001@163.com, \\ * Corresponding author
}

one is highway scene simulation which focus on the coordination of road and landscape, typical results are LADS DS which is from university of Leeds of UK [4], SmartPath which is from university of California of USA [5]; the other is the research results which achieve simulation capabilities of part of the traffic system, such as IHSDM system for highway alignment design [6], HYSIM for researching person's psychological and behavioral [7]. According the method of literature [8], the developing flow of simulation software of landscape affect traffic safety will be researched, and then the result will be achieved by operating the software. This work will provide effective means to research landscape affect traffic safety.

\section{DEVELOPMENT METHODS}

\section{A. Software Development Process}

1). Flow chart of main control program.

For acquire simulation results of different road environment, vehicle speed and landscape position were set as loop variable. The flow chart of main control program is shown in Fig.1.

2). Flow chart of main program.

The basic idea of the simulation of the main program is as following: in one loop, by using the parameter, the standard sight distance (shorted by SSD) will be set and the driver sight distance (shorted by DSD) will be calculated through the model [8], and then safety status of vehicle will be judged by comparing SSD and DSD. The number of vehicle run on the simulation road is the loop number, each time the safety status will be judged, the accident number will be recorded, and the probability of risk will be calculated by main control program after the simulating vehicle operated many times. The probability is the safety status of this road in a certain period. The flow chart of main program is as shown in Fig.2. 


\section{B. Simulation software development}

According the idea of the flow chart of program design, the simulation software of landscape affecting traffic safety was developed by Visual Basic and Access Database [8].

The simulation software was made of five modules; they are simulation model parameters entering module, driver sight distance calculation module, program controlling module, probability tendency chart of risk status module, and result outputting module. The basic operation flow of this program is as following: at first, there are four simulation models in simulation model parameters enter module, they are vehicle model, driver model, landscape model and road model, they must be set a value according the requirement of simulation; in the second, driver sight distance calculation module will be started, the DSD will be calculated, the SSD will be set; third, program controlling module will be started, after set the loop times, the program will run, and the result will be outputted; at last, the probability tendency chart of risk status module will be activated when program controlling module start, the probability tendency chart of risk status of the road will be outputted.
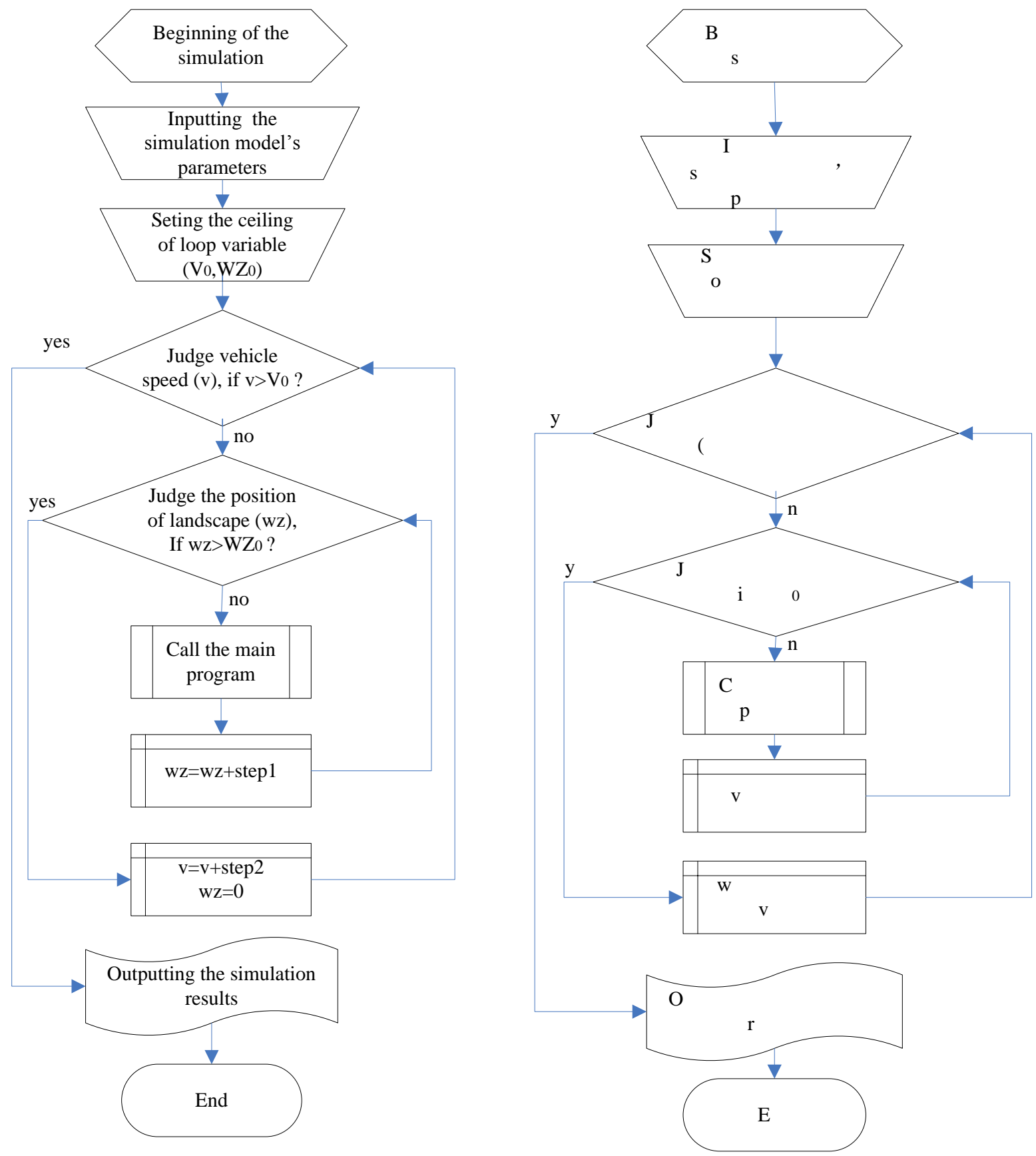

Fig.1. Two difference main controlling program flow chart 


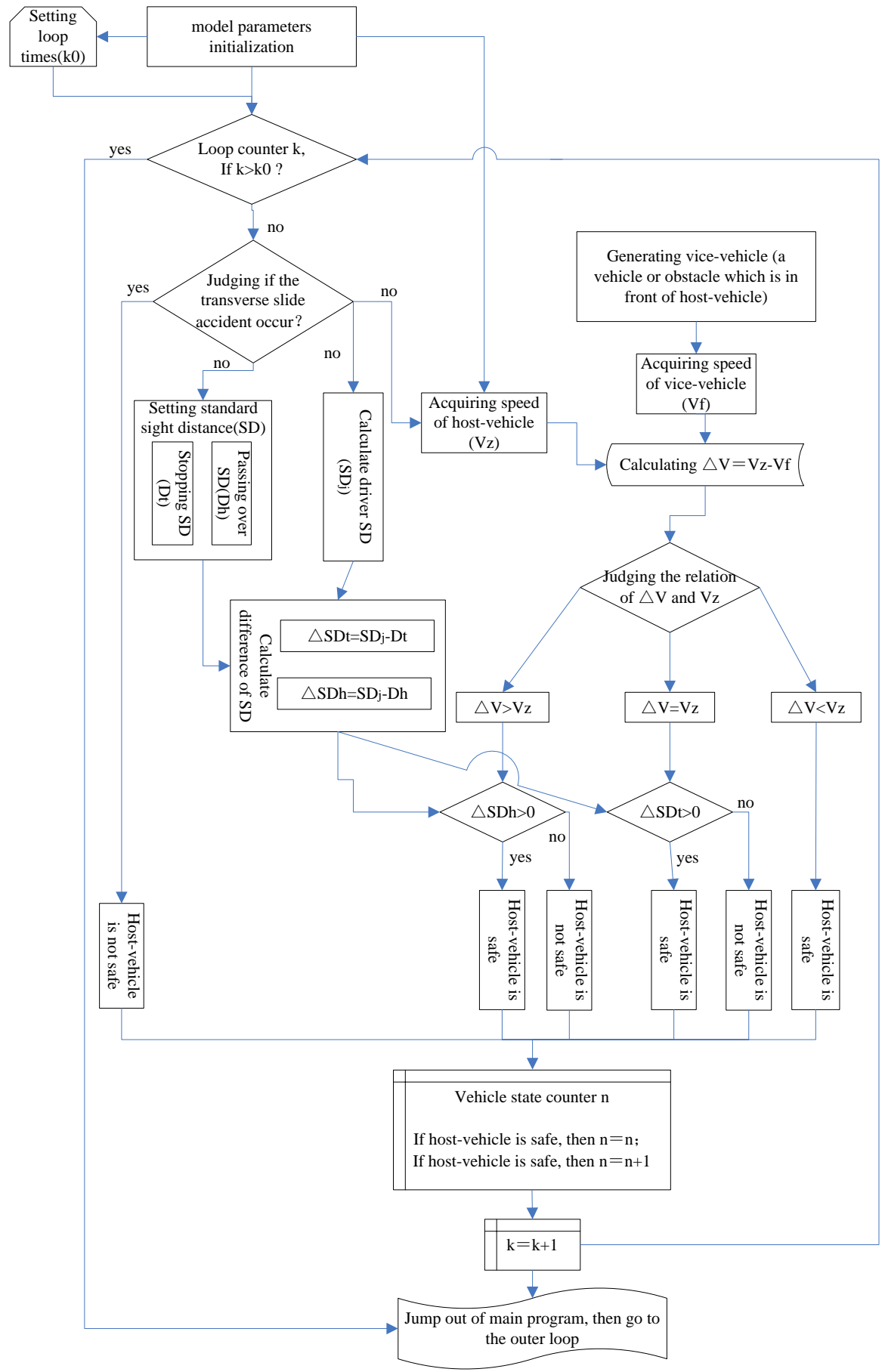

Fig.2. The main flow chart of simulation program

\section{III.AN EXAMPLE OF SIMULATION}

By using this simulation software, the result can be acquired at different radius of curved road, at different road design speed, and at different position of landscape. Here is a example, the road design speed was $60 \mathrm{~km} / \mathrm{h}$, the result was shown in Fig.3, in the legend, "1, 2, .., 6" is test group sequence, and "big, middle, small" is the radius of curved road.
Curved road was distinguished as following: when road design speed is $60 \mathrm{~km} / \mathrm{h}$, the radius of big radius curved road is not less than 400 meter, the radius of middle radius curved road is between 200 meter and 400 meter, the radius of small radius curved road is less than 200 meter; when road design speed is $60 \mathrm{~km} / \mathrm{h}$, the radius of big radius curved road is not less than 600 meter, the radius of middle radius curved road is between 300 meter and 600 meter, the radius of small radius curved road is less than 300 meter. 


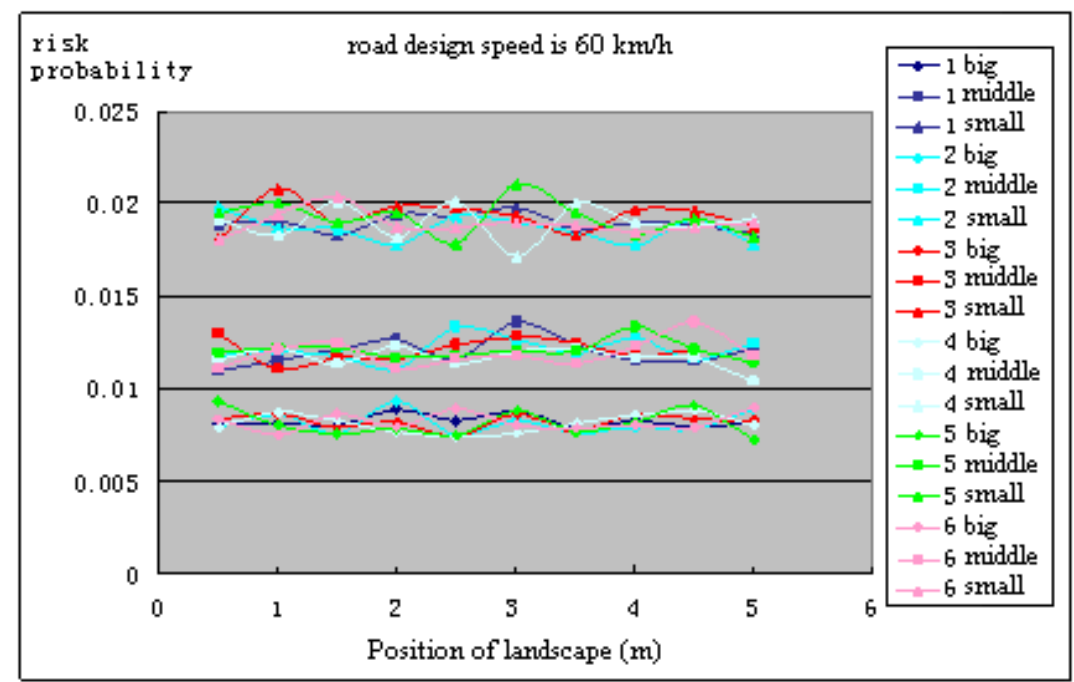

Fig.3. Graph of landscape position affect on the state of vehicle safety when design speed is $60 \mathrm{~km} / \mathrm{h}$

Run the simulation program when road design speed is 60 $\mathrm{km} / \mathrm{h}$ and $80 \mathrm{~km} / \mathrm{h}$, and compared the results, some rules were found. When road design speed and the position of landscape are same, the bigger the radius of road, the smaller the risk probability of the road is. For example, the risk probability of the road is 0.019 times per hundred vehicles in small radius road, however it is 0.008 times per hundred vehicles in big radius road, it was reduced about $58 \%$. When road design speed is same, the risk probability of the road is changed a little as the position of landscape changed. When radius of road is same, the bigger the road design speed, the smaller the risk probability of the road is. For example, the risk probability of the road is 0.012 times per hundred vehicles when the road design speed is $60 \mathrm{~km} / \mathrm{h}$, however it is 0.007 times per hundred vehicles when the road design speed is 80 $\mathrm{km} / \mathrm{h}$, it was reduced about $41.7 \%$.

\section{IV.CONCLUDING}

Development process of simulation software of landscape affecting traffic safety was researched, main controlling program flow chart and main flow chart of simulation program were built, and simulation software was developed by Visual Basic and Access Database. The simulation result was acquired by running the simulation program; the result showed that the risk probability of the road from landscape was influenced by road design speed, radius of curve road, position of landscape.

\section{ACKNOWLEDGEMENTS}

This work is financially supported by Youth Fund of National Natural Science Foundation of China (No. 51008142) and China Postdoctoral Science Foundation (No. 2011M500605).

\section{REFERENCE}

[1]. Wu Jiao-rong. Transport System Simulation and Application [M]. Shanghai: Tongji University Press, 2004.

[2]. DH Weir, et al. An Overview of the DRI Driving Simulator [J]. SAE Paper, 950173,1995.

[3]. Zhao You-qun, Guan Xing, Guo Kong-hui. Development of Driving Simulator [J]. Journal of Highway and Transportation Research and Development, vol 12(3),1995:64-66

[4]. Blana E.A. Survey of driving research simulators around the world [D]. Leeds, England: University of Leeds, 1996.

[5]. PATHPublications. Computer Simulation Issue SmartPath Simulation. www.path.berkeley.edu/PATH/Intellimotion, 2004.

[6]. Federal Highway Administration. Interactive Highway Safety Design Model (IHSDM). http://www.tfhrc.gov/safeth/ihsdm. 2004.

[7]. Ward N J, Beusmans J. Simulation of Accident Risk Display in Motorway Driving with Traffic [J]. Ergonomics, 1998, 41.

[8]. Yang Zhifa. Research on comprehensive evaluation and simulation method for the impact of high-grade highway landscape on driving safety [D]. Changchun, China: Jilin University, 2007. 